\title{
Delayed tooth eruption and its pathogenesis in paediatric patient: a review
}

\begin{abstract}
Human eruption is a unique developmental process in the organism. Delayed tooth eruption is the emergence of a tooth into the oral cavity at a time that deviates significantly from norms established for different races, ethnicities, and sexes. The eruption time of primary teeth is very important for planning and diagnosing of certain growth developments. The present article gave a review on delayed tooth eruption and its pathogenesis.
\end{abstract}

Keywords: delayed tooth eruption, oral cavity, eruption
Volume 10 Issue $3-2019$

\author{
Haneen Alshukairi \\ Preventive Department, Pediatric Division, Riyadh ELM \\ University, Saudi Arabia
}

Correspondence: Haneen Alshukairi, Preventive Department, Pediatric Division, Riyadh ELM University, Saudi Arabia, Email haneen@doctor.com,drhaneensh@riyadh.edu.sa

Received: May 22, 2019 | Published: May 28, 2019

\section{Introduction}

Tooth eruption is the process by which developing teeth emerge through the soft tissues of the jaws and the overlying mucosa to enter the oral cavity, contact the teeth of opposing arch, and function in mastication. ${ }^{1}$ The term "eruption" is derived from the Latin word "erupptione," which means output with momentum. ${ }^{2}$ It is a continuous process that ends only with the loss of tooth. Eruption of deciduous teeth, their exfoliation followed by eruption of permanent dentition is an orderly, sequential, and age-specific event and is considered as an important milestone during child's development. ${ }^{3}$ Parents consider eruption of first primary teeth as an important developmental milestone that has to be achieved by the child. ${ }^{4,5}$ Eruption is a physiologic process that strongly influences the normal development of the craniofacial complex. . $^{67}$

Pathogenesis and aetiology: The process of normal eruption and the source of eruptive forces are still controversial topics. Some local and systemic factors may affect the pattern of eruption. Others factors affect the timing of eruption.

Local conditions causing delayed eruption include:

Physical obstruction: These obstructions can result from many different of causes, such as supernumerary teeth, mucosal barrier, scar tissue, and tumors. It has been reported to occur in $28 \%$ to $60 \%$ of white people with supernumerary teeth. ${ }^{8}$

Mucosal barrier has also been suggested as an etiologic factor in delayed teeth eruption ${ }^{9-12}$

Gingival hyperplasia due to hormonal imbalance, hereditary causes, vitamin $\mathrm{C}$ deficiency or phenytoin drugs cause increase of dense connective tissue and the acellular collagen that can affect the normal tooth eruption. ${ }^{13}$

Traumatic injuries can lead to ectopic eruption 35,36 or some disruption in normal odontogenesis in the form of dilacerations ${ }^{14,15}$ or physical displacement of the permanent germ. ${ }^{16,17}$

Cystic transformation of a nonvital deciduous incisor might also cause delay in the eruption of the permanent successor. ${ }^{18}$

Ankylosis, the fusion of the cementum or dentin to the alveolar bone, is the most common local cause of delayed deciduous tooth exfoliation. ${ }^{19-24}$
Arch-length deficiency is often mentioned as an etiologic factor for crowding impactions. ${ }^{19,20}$

Systemic conditions include:

The effect of nutritional deficiency on tooth eruption have been reported. ${ }^{24-26}$

Disturbance of the endocrine glands usually has a profound effect on the entire body, including the dentition. The dentofacial changes in cretinism are related to the degree of thyroid deficiency. ${ }^{7-29}$ In pituitary dwarfism, eruption and shedding of teeth are delayed, as is the growth of the body in general..$^{27,30,31}$ Retardation of dental growth and development in preterm babies has been reviewed by Seow and identified as a cause of delayed Tooth Eruption. ${ }^{32}$ Patients with human immunodeficiency virus (HIV) infection showed delayed tooth Eruption. A study of dental manifestations in 70 children perinatally infected with HIV reported that delayed dental eruption. ${ }^{33}$ In a study of children with cerebral palsy, Pope and Curzon found that unerupted deciduous and permanent teeth were more common in them compared with the controls. The first permanent molar erupted significantly later. No etiology or implicated mechanisms were elaborated. ${ }^{34}$ Other systemic conditions associated with impairment of growth, such as anemia (hypoxic hypoxia, ${ }^{35}$ histotoxic hypoxia, and anemic hypoxia ${ }^{35}$ ) and renal failure, ${ }^{36}$ have also been correlated with delayed Tooth Eruption and other abnormalities in dentofacial development.

Genetic disorders: A generalized developmental delay in permanent tooth formation is seen in Apert syndrome. ${ }^{37,38}$ Supernumerary teeth have been found to be responsible for deleyed Tooth Eruption in Apert syndrome, ${ }^{37,39}$ cleidocranial dysostosis, ${ }^{40}$ and Gardner syndrome. ${ }^{41}$

\section{Factors affecting the eruption time}

Several studies have shown variations in the ages at which individual primary teeth erupt as well as variations of eruption pattern between different ethnic and racial groups. ${ }^{7,8}$ Other suggested factors, which affect the eruption time, may include gestational period, diseases, nutritional status, growth and climate. In addition to genetic factors, environmental factors such as maternal smoking, height and weight of a new born at the time of birth and nutrition status has shown to play a role in the eruption of the first primary tooth. A few reports have focused on the discerning effect of nutrition in early age of a child, including breast milk. 
Factors affecting eruption:

\section{Weight of children:}

- Low birthweight: Seow reviewed and identified retardation of dental growth and development in preterm babies. ${ }^{32}$

- In another study, Seow found that children with a birth weight less than $1000 \mathrm{~g}$ and gestational ages less than 30 weeks had the greatest lag in dental maturation. ${ }^{42}$

- Malnutrition: The extremes of nutritive deprivation that the effects on tooth eruption have been shown. ${ }^{24-26}$

2. Height: There were also significant associations between the total number of teeth present and height, weight and head circumference in boys; the associations in girls were significant for teeth vs. height. These findings indicate that the timing of deciduous tooth emergence is significantly related to general somatic growth and perhaps nutritional status. ${ }^{43}$

3. Breast feeding: Exclusive breastfeeding has an overall effect on growth and development of children. ${ }^{44}$ Various studies have noted the effect of breastfeeding habits on orofacial development, including eruption of primary and permanent dentitions. ${ }^{45}$ Larsson et al. found that there was an increased dribble and biting or gnawing activity, especially around the eruption area during teething time. ${ }^{46}$

4. Maternal age: The GUSTO study in Singapore, which uncovered an association between higher maternal childbearing age and earlier eruption timing of first primary tooth in infants. ${ }^{47}$

5. Socioeconomic status: Clemens et al. in 1953 claimed the mean emergence times of children in a higher socio-economic group tended to be earlier than those in other children. ${ }^{48}$

6. Climate : Al-Jasser NM et al considered many reasons as influential factors on the time and order of teeth emergence. These include nutrition, socioeconomic status, sex, climate, and premature extraction of the deciduous teeth. ${ }^{49}$

7. Race: A study of dental patterns among Saudi Arabian children showed that they experienced delayed first primary tooth eruption when compared to Caucasian children (including children from Iceland and US). ${ }^{49}$

8. Diseases: The dentofacial changes in cretinism are related to the degree of thyroid deficiency. ${ }^{27-29}$ In hypopituitarism or pituitary dwarfism, the eruption and shedding of the teeth are delayed, as is the growth of the body in general. ${ }^{27,30,31}$ Other systemic conditions associated with impairment of growth, such as anemia (hypoxic hypoxia ${ }^{35}$ histotoxic hypoxia, and anemic hypoxia) ${ }^{35}$ and renal failure ${ }^{36}$ have also been correlated with Delayed Tooth Eruption and other abnormalities in dentofacial development.

Several studies have considered influential factors such as nutrition, socio-economic status climate, and premature extraction of deciduous teeth on the time and order of the emergence of teeth, but the results were inconsistent. ${ }^{8,9}$ For example, Clemens et al. (1953) claimed the mean emergence times of children in a higher

socio-economic group tended to be earlier than those in other children.10 Furthermore, other studies suggested a genetic origin for early or late emergence of teeth.11-14 But Lee et al. (1965) emphasized the inter-population differences seemed to have little meaning in themselves unless the socio-economic conditions, nutritional

Several studies have considered influential factors such as nutrition, socio-economic status, climate, and premature extraction of deciduous teeth on the time and order of the emergence of teeth, but the results were inconsistent. ${ }^{8,9}$

For example, Clemens et al. ${ }^{48}$ claimed the mean emergence times of children in a higher socio-economic group tended to be earlier than those in other children.10 Furthermore, other studies suggested a genetic origin for early or late emergence of teeth.11-14 But Lee et al. (1965) emphasized the inter-population differences seemed to have little meaning in themselves unless the socio-economic conditions, nutritional.

Several studies have considered influential factors such as nutrition, socio-economic status, climate, and premature extraction of deciduous teeth on the time and order of the emergence of teeth, but the results were inconsistent. ${ }^{8,9}$

For example, Clemens et al. ${ }^{48}$ claimed the mean emergence times of children in a higher socio-economic group tended to be earlier than those in other children. 10 Furthermore, other studies suggested a genetic origin for early or late emergence of teeth.11-14 But Lee et al. (1965) emphasized the inter-population differences seemed to have little meaning in themselves unless the socio-economic conditions, nutritional

\section{Comparison between eruption pattern in Saudi Arabia}

A study by Al-Jasser NM et al. ${ }^{49}$ compares the eruption pattern in the children of Saudia Arabia. For both the maxilla and mandible, there were no differences in the mean age of eruption of the teeth in the right and left sides; hence, they were combined. The mandibular central incisors were the earliest category of teeth to erupt with a mean age of about 8.5 months for both genders. A standard deviation of 2.8 months suggests $68 \%$ of the children would have their teeth erupted between 5.7 months and 11.3 months. The maxillary central incisors erupted at about 11 months followed by the maxillary and mandibular laterals respectively. The first molars erupted on average earlier than the canines. The mandibular and maxillary second molars erupted at a mean age of about 28 months for both genders. The length of time from eruption of the first tooth to the last tooth was 19.5 months in the mandible and almost 17 months in the maxilla. The phases of eruption of primary teeth were divisible into 4 active periods: incisors; first molars; canines; and second molars, with an interval of rest between the phases. The first phase comprised central and lateral incisors that erupted within 6 months in both jaws for boys and girls. An interval of about 2.6 months in the mandible and 3.7 months in the maxilla followed before eruption of the first molars. The third phase commenced with eruption of canines after a resting period of 3.9 months in the mandible and 4.2 months in the maxilla. The last phase was the eruption of the second molars that occurred after a pause of about 6.9 and 7.1 months in the mandible and maxilla respectively. There is a tendency for the teeth to erupt earlier in boys in both the maxilla and mandible. The results of this study were compared to those of similar studies involving varying racial and ethnic groups. They suggest a slightly delayed eruption of the teeth in Saudi children compared to those of Caucasian children, but the results were similar to those reported for Iraqi children. ${ }^{49}$ 


\section{Conclusion}

Variation in the normal eruption of teeth is a common finding, but significant deviations from established norms should alert the clinician to further investigate the patient's health and development. Delayed tooth eruption might be indication of a systemic condition or an indication of altered physiology of the craniofacial complex.

\section{Acknowledgments}

None.

\section{Conflicts of interest}

The author declares that there is no conflict of interest.

\section{References}

1. Avery JK, Steele PF, Avery N. Oral development and histology. $3^{\text {rd }}$ ed German: Thieme Medical Publishers; 2002:123-124.

2. Neto PG, Falcão MC. Eruption chronology of the first deciduous teeth in children born prematurely with birth weight less than $1500 \mathrm{~g}$. Rev Paul Pediatr. 2014;32(1):17-23.

3. Peedikayil FC. Delayed tooth eruption. e-J Dent. 2011;1(4):81-86.

4. Indira MD, Nandlal B, Narayanappa D, et al. Perception about teething among the nursing mothers of Mysore. J Int Med Dent. 2016;3:119-125.

5. Peretz B, Ram D, Hermida L, et al. Systemic manifestations during eruption of primary teeth in infants. J Dent Child (Chic). 2003;70(2):170-173.

6. Nolla CM. The development of the human dentition. ASDC J Dent Child. 1960;27:254-266

7. Krogman WM. Biological timing and the dento-facial complex. 3. J Dent Child. 1968;35(4):328-41.

8. Tay F, Pang A, Yuen S. Unerupted maxillary anterior supernumerary teeth: report of 204 cases. ASDC J Dent Child. 1984;51(4):289-294.

9. Tomizawa M, Yonemochi H, Kohno M, et al. Unilateral delayed eruption of maxillary permanent first molars: four case reports. Pediatr Dent. 1998;20(1):53-56.

10. Di Biase DD. Mucous membrane and delayed eruption. Dent Pract Dent Rec. 1971;21(7):241-250.

11. Di Biase DD. Mucous membrane and delayed eruption. Trans Br Soc Study Orthod. 1969;5(6):149-58.

12. Goho C. Delayed eruption due to overlying fibrous connective tissue ASDC J Dent Child. 1987;54(5):359-360.

13. Katz J, Guelmann M, Barak S. Hereditary gingival fibromatosis with distinct dental, skeletal and developmental abnormalities. Pediatr Dent. 2002;24(3):253-256.

14. Andreasen JO, Sundstrom B, Ravn JJ. The effect of traumatic injuries to primary teeth on their permanent successors. I. A clinical and histologic study of 117 injured permanent teeth. Scand J Dent Res. 1971;79(4):219-283

15. Andreasen JO, Andreasen FM. Textbook and color atlas of traumatic injuries to the teeth. Copenhagen: Munksgaard; 1994.

16. Brin I, Ben-Bassat Y, Zilberman Y, et al. Effect of trauma to the primary incisors on the alignment of their permanent successors in Israelis. Community Dent Oral Epidemiol. 1988;16(2):104-108.

17. Hawes RR. Traumatized primary teeth. Dent Clin North Am. 1966:391-404
18. Yawaka Y, Kaga M, Osanai M, et al. Delayed eruption of premolars with periodontitis of primary predecessors and a cystic lesion: a case report Int J Paediatr Dent. 2002;12(1):53-60.

19. Raghoebar GM, Boering G, Vissink A, et al. Eruption disturbances of permanent molars: a review. J Oral Pathol Med. 1991;20(4):159-166.

20. Andreasen JO, Petersen JK, Laskin DM. Textbook and color atlas of tooth impactions. St. Louis: Mosby; 1997.

21. Raghoebar GM, Boering G. An unerupted deciduous molar. Oral Surg Oral Med Oral Pathol. 1991;71(4):521-522.

22. Biederman W. The problem of the ankylosed tooth. Dent Clin North Am. 1968:409-424

23. Brearley LJ, McKibben DH Jr. Ankylosis of primary molar teeth. I. Prevalence and characteristics. J Dent Child. 1973;40(1):54-63.

24. Alvarez JO. Nutrition, tooth development, and dental caries. Am J Clin Nutr. 1995;61(2):410S-416S.

25. Garn SM, Rohmann CG. Interaction of nutrition and genetics in the timing of growth. Pediatr Clin North Am. 1966;13(2):353-379.

26. Moyers RE. Handbook of orthodontics. Chicago: Year Book Medical Publishers; 1988

27. Shaw L, Foster TD. Size and development of the dentition in endocrine deficiency. J Pedod. 1989;13(2):155-160.

28. Loevy HT, Aduss H, Rosenthal IM. Tooth eruption and craniofacial development in congenital hypothyroidism: report of case. J Am Dent Assoc. 1987;115(3):429-431.

29. Hinrichs EH Jr. Dental changes in juvenile hypothyroidism. ASDC J Dent Child. 1966;33:167-173.

30. Kosowicz J, Rzymski K. Abnormalities of tooth development in pituitary dwarfism. Oral Surg Oral Med Oral Pathol. 1977;44(6):853-863.

31. Kjellberg H, Beiring M, Albertsson Wikland K. Craniofacial morphology, dental occlusion, tooth eruption, and dental maturity in boys of shor stature with or without growth hormone deficiency. Eur J Oral Sci. 2000;108(5):359-67.

32. Seow WK. Effects of preterm birth on oral growth and development. Aust Dent J. 1997;42(2):85-91.

33. Hauk MJ, Moss ME, Weinberg GA, et al. Delayed tooth eruption: association with severity of HIV infection. Pediatr Dent 2001;23(3):260-262.

34. Pope JE, Curzon ME. The dental status of cerebral palsied children Pediatr Dent. 1991;13(3):156-162.

35. Giglio MJ, Sanz AM, Bozzini CE. Depressed eruption rate of the rat maxillary incisor in a drug-induced uncompensated hemolytic state model. J Dent Res. 1990;69(3):906-908.

36. Giglio MJ, Frid A, Barcat JA, et al. Depressed eruption dental rate in rats with hemodynamically mediated acute renal failure. Acta Odontol Latinoam. 1994;8(1):27-37.

37. Kaloust S, Ishii K, Vargervik K. Dental development in Apert syndrome. Cleft Palate Craniofac J. 1997;34(2):117-121.

38. Kreiborg S, Cohen MM Jr. The oral manifestations of Apert syndrome. $J$ Craniofac Genet Dev Biol. 1992;12(1):41-48.

39. Gorlin RJ, Cohen MMJ, Hennekam RCM. Syndromes of the head and neck. New York: Oxford University Press; 2001.

40. Jensen BL, Kreiborg S. Development of the dentition in cleidocranial dysplasia. J Oral Pathol Med. 1990;19(2):89-93. 
41. Buch B, Noffke C, de Kock S. Gardner's syndrome - the importance of early diagnosis: a case report and a review. SADJ. 2001;56(5):242-245.

42. Seow WK. A study of the development of the permanent dentition in very low birthweight children. Pediatr Dent. 1996;18(5):379-384.

43. Infante PF, Owen GM. Relation of chronology of deciduous tooth emergence to height, weight and head circumference in children. Arch Oral Biol. 1973;18:1411-1417.

44. Ahn $\mathrm{CH}$, MacLean WC Jr. Growth of the exclusively breast-fed infant. Am J Clin Nutr. 1980;33(2):183-192.

45. Sahin F, Camurdan AD, Camurdan MO, et al. Factors affecting the timing of teething in healthy Turkish infants: a prospective cohort study. Int $J$ Paediatr Dent. 2008;18(4):262-266.
46. Larsson E. Sucking, chewing, and feeding habits and the development of crossbite: a longitudinal study of girls from birth to 3 years of age. Angle Orthod. 2001;71(2):116-119.

47. Un Lam C. Influence of metabolic-linked early life factors on the eruption timing of the first primary tooth. J Clin Oral Investig. 2016;20(8):18711879 .

48. Clements EMB, Davids-Thomas E, Pickett KG. Time of eruption of permanent teeth in British children in 1947-8. $\mathrm{Br}$ Med $\mathrm{J}$. $1953 ; 1(4825): 1421-1424$.

49. Al-Jasser NM, Bello LL. Time of eruption of primary dentition in children from Saudi Arabia. J Contemp Dent Pract. 2003;4(3):65-75. 